\title{
CONTRIBUIÇÕES DA LUDOPEDAGOGIA: O LÚDICO NAS SÉRIES INICIAIS
}

\author{
Crist Wilian de Moura Barbosa da Silva ${ }^{1}$ \\ David Anderson Barbosa Rodrigues ${ }^{2}$ \\ Robson Canteiro Valenzuela ${ }^{3}$ \\ Rosilene de Arruda Assunção ${ }^{4}$ \\ Uetes do Carmo Santos 5 \\ Wanderson Rodrigues Miranda ${ }^{6}$
}

RESUMO: A educação escolar demanda ser repensada e aprimorada continuamente, pois decorrem mudanças na sociedade que influenciam nas necessidades $e$ concepções do indivíduo. neste contexto, o lúdico constitui a sua importância no desenvolvimento do aprendizado das crianças das séries iniciais, por meio dos jogos e brincadeiras. este estudo qualifica-se como uma pesquisa bibliográfica. o objetivo geral deste estudo é discutir o trabalho com estratégias de ensino lúdicas nas séries iniciais. o desenvolvimento deste estudo se justifica pela abrangência do componente lúdico nas estratégias de ensino que são empregadas nas séries iniciais. as estratégias de ensino lúdicas são embasadas pelos conhecimentos difundidos na ludopedagogia, se expressando por meio de atividades lúdicas de jogos, brincadeiras e dinâmicas. estas estratégias de ensino lúdicas se desenvolvem embasadas na criatividade e curiosidade da criança, contribuindo para o aluno se posicionar como agente ativo na construção dos eu conhecimento.

\footnotetext{
I Pós-graduado em Docência do Ensino Superior pela Faculdade Brasileira de Educação e Cultura. Pós-graduado em Atendimento Educacional Especializado pela Faculdade de Administração, Humanas e Exatas. Licenciado em Geografia pela UNIP. Licenciado em Pedagogia pela Faculdade Delta. e-mail:cristwilian@hotmail.com.

2 Pós-graduado em Educação Infantil e Anos Iniciais pela Fundação Cesumar (UniCesumar). Licenciado em Pedagogia pela Faculdade Integrada de Araguatins (FAIARA). E-mail: davidanderson.rodrigues@gmail.com.

3 Graduação em Artes Cênicas - Licenciatura pela Universidade Federal da Grande Dourados. Pósgraduação em Artes Visuais pela Faculdade Venda Nova do Imigrante - FAVENI. Segunda Licenciatura em Pedagogia na Faculdades Magsu. E-mail:robinn.valenzuela@gmail.com.

${ }^{4}$ Graduada em Letras pela UNIVAG - Centro Universitário de Várzea Grande. Pós-graduada em: Educação Infantil com ênfase em Educação Especial pela Faculdade de Educação de Tangará da Serra. Segunda Licenciatura em Pedagogia pelo UNIJALES - Centro Universitário de Jales. E-mail: rosiprofvg@gmail.com.

5 Pós-graduado em Educação Infantil e Ensino Fundamental (UNIP-DF). Pós -graduado em Docência do Ensino Superior pela Faculdade de Ciências de Wenceslau Braz (Facibra). Licenciado em Educação Física Universidade Paulista (UNIP). E- mail: pefprofessor@gmail.com.

6 Graduado em Licenciatura em Computação pelo Instituto Federal de Educação, Ciência e Tecnologia do Tocantins. Graduado em Licenciatura em Educação Física pela Universidade Norte do Paraná. Graduado em Licenciatura em Pedagogia pelas Faculdades Integradas de Itararé - FAFIT; Pós-graduando em Educação Infantil e Ensino Fundamental pela Faculdade FAMART. E-mail: miranda.wanderson@gmail.com.
} 
Palavras-chave: Ludopedagogia. Educação Infantil. Ludicidade. Estratégias de Ensino. Atividades Lúdicas.

ABSTRACT: School education demands to be continually rethought and improved, as changes occur in society that influence the individual's needs and conceptions. in this context, the playful constitutes its importance in the development of learning for children in the early grades, through games and games. this study qualifies as a bibliographic research. the general objective of this study is to discuss the work with playful teaching strategies in the early grades. the development of this study is justified by the scope of the playful component in the teaching strategies that are used in the early grades. playful teaching strategies are based on the knowledge disseminated in ludopedagogy, expressed through playful activities of games, games and dynamics. these playful teaching strategies are developed based on the child's creativity and curiosity, helping the student to position himself as an active agent in the construction of his knowledge.

Keywords: Ludopedagogy. Child Education. Playfulness. Teaching Strategies. Playful Activities.

\section{INTRODUÇÃO}

A educação escolar demanda ser repensada e aprimorada continuamente, pois decorrem mudanças na sociedade que influenciam nas necessidades e concepções do indivíduo. A inserção das tecnologias na vida dos alunos evidencia a importância da inovação nas práticas pedagógicas, mas demonstra também o interesse pelo resgate de estratégias de ensino. Os jogos e brincadeiras estão sendo resgatados na aprendizagem dos alunos, em decorrência da ludicidade presente nestas estratégias de ensino.

As tecnologias são ferramentas de apoio, se isoladas não garantem o aprendizado das crianças. Neste contexto, o lúdico constitui a sua importância no desenvolvimento do aprendizado das crianças das séries iniciais, por meio dos jogos e brincadeiras. Desta maneira, apresenta-se a questão problema para direcionar o desenvolvimento deste estudo em sua abordagem: Quais as contribuições da Ludopedagogia para o processo de ensino-aprendizagem das séries iniciais?

O objetivo geral deste estudo é discutir as contribuições da Ludopedagogia para o processo de ensino-aprendizagem dos alunos das séries iniciais. Os objetivos 
específicos são os seguintes: abordar sobre a Ludopedagogia e os seus aspectos; refletir sobre a ludicidade; e refletir sobre o desenvolvimento de estratégias de ensino lúdicas nas séries iniciais.

O desenvolvimento deste estudo se justifica pela abrangência do componente lúdico nas estratégias de ensino que são empregadas nas séries iniciais. Estas estratégias de ensino precisam ser discutidas, para se compreender o desenvolvimento do seu componente lúdico, na promoção do desenvolvimento da aprendizagem dos alunos das séries iniciais. Além disso, estas estratégias de ensino precisam se inovadas continuamente, para não se perder o seu componente lúdico, pois as crianças mudam as suas concepções no processo histórico da sociedade.

Este estudo qualifica-se como uma pesquisa bibliográfica, que se desenvolveu a partir do levantamento em artigos científicos, monografias, livros, dissertações de Mestrado e teses de Doutorado. Inicialmente, abordou-se sobre a Ludopedagogia, com enfoque nas suas contribuições para o desenvolvimento do componente lúdico na educação escolar. Sequencialmente, refletiu-se sobre o lúdico e sua presença na educação escolar. Finalmente, refletiu-se sobre o desenvolvimento das estratégias de ensino lúdicas nas séries iniciais, com enfoque no desenvolvimento do aprendizado das crianças.

\section{Ludopedagogia e suas contribuições}

A ludopedagogia possibilita visualizar o alinhamento da prática pedagógica com o componente lúdico na aprendizagem das crianças. Lopes (2013) enfatiza que a ludopedagogia detém o objetivo de proporcionar um processo de ensino criativo, por meio das estratégias de jogos, brincadeiras e dinâmicas. A metodologia da ludopedagogia se embasa no componente lúdico aplicado nas estratégias de ensino.

Silva (2012) observa que o lúdico consiste no emprego da ilusão para a construção de uma estratégia de ensino configurada na brincadeira ou jogo, vinculando-a à alegria e ao prazer promovidos na atividade. De acordo com a autora, a ludopedagogia potencializa um amplo desenvolvimento das habilidades por meio 
das brincadeiras, e possibilita que o ato de educar abandone a condição de apenas transmissão de informações.

Calabresi (2015) visualiza a ludopedagogia como um recurso facilitador no processo de ensino-aprendizagem, demanda-se a observação e atenção no contexto envolvido na ação das crianças. A referida autora complementa que a mediação do professor envolve também a seleção das atividades para a construção do conhecimento, considerando as necessidades lúdicas de cada aluno. A ludopedagogia promove uma metodologia de ensino que dialoga com o desenvolvimento do aluno, por meio dos conhecimentos pedagógicos e interdisciplinares.

Freire (20II) salienta que o desenvolvimento de uma atividade lúdica possibilita e facilita a aprendizagem, o desenvolvimento pessoal, social e cultural, colabora para uma boa saúde mental e prepara para um estado interior fértil. O referido autor observa que as atividades lúdicas auxiliam na socialização, na comunicação, na expressão e na construção do conhecimento. Neste contexto, a ludopedagogia proporciona bases metodológicas para se desenvolver e explorar a ludicidade dos jogos e brincadeiras no processo de ensino-aprendizagem.

Alves, Batista e Paulo (2019) visualizam a ludopedagogia como uma nova vertente educacional, pois possibilita a criança desenvolver a sua imaginação, a sua relação com outras pessoas do seu cotidiano e a sua capacidade de aquisição de novos conhecimentos. Os referidos autores destacam que as atividades ludopedagógicas envolvem um brincar intencional, com objetivo, pois não caracterizam como meramente instrucionais ou de acompanhamento na promoção de habilidades e competências específicas.

A ludopedagogia potencializa estratégias de ensino que possibilitam ao professor trabalhar o processo de ensino-aprendizagem perante os desafios das séries iniciais. Mariano (2012) aborda que a educação proporciona muitos desafios aos professores e especialistas, pois envolve diversas metodologias de ensino e seus respectivos recursos didáticos, para a escola se tornar um lugar que desperte o interesse da criança em aprender. Santos (20II) contempla que uma educação significativa e de qualidade demanda pensar na totalidade do ser humano, 
considerando o seu ambiente, as suas preferências, os seus prazeres e as suas relações vivenciadas. $O$ desenvolvimento das atividades ludopedagógicas consideram a criança em sua totalidade, para explorar as potencialidades do lúdico no desenvolvimento dela.

Calabresi (2015) ressalta que os professores devem estar atentos na seleção de materiais adequados para cada faixa etária e as demandas dos alunos, pois a mediação deve ter um enfoque na aprendizagem criativa e social. Na seleção, o professor deve contemplar os objetivos definidos para as atividades ludopedagógicas, considerando o desenvolvimento das crianças no processo de ensino-aprendizagem.

Além dos conhecimentos pedagógicos, o professor se utiliza de suas habilidades emocionais para promover a ludicidade nas atividades ludopedagógicas aplicadas em sala de aula. Luckesi (2014) destaca que o professor deve estar atento e administrar as suas reações emocionais, pois são fundamentos importantes para desenvolver relações saudáveis com os alunos e se manter lúdico dentro de si. Mariano (2012) enfatiza que o professor deve fazer parte da brincadeira no ambiente lúdico, pois impulsiona o nível de interesse e participação dos alunos no processo de ensino-aprendizagem. A ludicidade se desenvolve na educação escolar, por meio de atividades de brincadeiras e jogos que são transformadas em atividades ludopedagógicas.

\section{I.I O lúdico na educação escolar}

A educação escolar demanda um ambiente e práticas pedagógicas que sejam atraentes aos alunos, reconhecendo-os como sujeitos do seu aprendizado. Luckesi (2014) aborda a ludicidade como um estado interno do sujeito, pertencente a dimensão subjetiva individual. O referido autor complementa que as atividades lúdicas e ludicidade são fenômenos diversos, pois elas pertencem ao domínio externo ao sujeito e se configura na dimensão objetiva coletiva. Estas definições epistemológicas devem ser trabalhadas nas atividades ludopedagógicas empregadas no processo de ensino-aprendizagem das séries iniciais.

Mineiro e D'Ávila (2019) defendem que a ludicidade se constitui um potencializador de aprendizagem, de ensino e de mediações na formação. De acordo 
com estes autores, há três dimensões no conceito de ludicidade: cultural, as atividades lúdicas são atos relacionais e sociais; psicológica, envolve um estado de ânimo expresso por sentimentos; e pedagógica, formativa e estruturante do processo de ensinar e aprender significativamente. Estas dimensões são observadas nas brincadeiras, nos jogos e nas dinâmicas, para identificação da ludicidade nestas atividades.

Bezerra (2009) compreende que o lúdico deve estar presente no cotidiano escolar por diversas manifestações, não se restringindo aos jogos, brincadeiras e atividades recreativas, pois é uma ferramenta de ensino com objetivo de dinamizar o processo de ensino-aprendizagem. A referida autora destaca que o ato de ensinar está relacionado à construção do conhecimento e ao desenvolvimento do cidadão, por isso as atividades lúdicas devem ser incentivadas e inovadas para valorizar a expressão do aluno.

Cordazzo et al (2007) enfatizam que o ato de brincar consiste em uma atividade que estimula o desenvolvimento físico e sensorial, principalmente nos aspectos perceptivos, motores, emocionais, sociais e cognitivos. Silva (2012) define que os jogos se constituem atividades estimulantes da criatividade, que podem ser empregadas nas práticas pedagógicas para promover o desenvolvimento do raciocínio e da aprendizagem, com a criança no papel interativo. As concepções destas atividades se agregam ao componente lúdico, no desenvolvimento do processo de ensino-aprendizagem.

Kishimoto (2010) observa que o brincar proporciona o poder de decisão e de pressão de sentimentos e valores à criança. Votto e Porciúncula (2017) ressaltam que o ato de brincar possibilitam a repetição de ações prazerosas, de partilhar, de expressão da sua individualidade e identidade, por meio de diversas linguagens decorrentes do corpo, dos sentidos e dos movimentos. As referidas autoras salientam que o brincar e a ludicidade são alinhados à prática educativa, considerada toda a sua complexidade.

A prática educativa se desenvolve na condição de uma atividade de manifestação da ludicidade. Mineiro e D’Ávila (2019) ressaltam que as manifestações 
da ludicidade podem se desenvolver em qualquer tempo, contexto ou idade, envolve negociação, protagonismo e decisão, demonstrando as capacidades transformadoras de aprender a aprender e a possibilidade de construção de artefatos de ludicidade, embasando as atividades de jogar, brincar, recrear e lazer. Lopes (2013) aborda a intercompreensão de compartilhar vivências na totalidade em um contexto de três tipos de comunicações: taxionômica, referente ao interacionismo simbólico e pragmático; ontológica, referente à consequencialidade; e etimológica, junção de sentidos na diversidade de manifestações.

Cervinski (2019) a ludicidade se constitui um recurso pedagógico, mas o seu caráter educativo é corroborado na identificação do despertar da curiosidade no aluno, pois deve possibilitar o aluno construir conceitos, selecionar ideias, definir relações lógicas, a integração de percepções, estabelecer estimativas de crescimento e desenvolvimento, e se socializar. A referida autora ressalta que o estímulo à criatividade contribui para a formação de um aluno mais empenhado e com anseio por novas descobertas, e mais participativo nos ambientes escolar e social.

A ludopedagogia possibilita se aprofundar na abordagem da ludicidade no contexto escolar e social, identificando as estratégias de ensino lúdicas que podem ser aplicadas ao processo de ensino-aprendizagem das séries iniciais. As estratégias de ensino lúdicas se desenvolvem por meio de diversas atividades, se utilizando de recursos didáticos e contextualizadas para a aprendizagem dos alunos das séries iniciais.

\subsection{Estratégias de ensino lúdicas nas séries iniciais}

As séries iniciais se constituem um processo de transição entre a educação infantil e as séries finais do ensino fundamental, evidenciando o desenvolvimento da criança na capacidade de aprendizagem no processo educacional. Santos e Ghelli (2015) ressaltam que o processo de ensino-aprendizagem das séries iniciais do ensino fundamental demanda que o professor observe e compreenda as formas de aprendizagem das crianças, as condições e objetos necessários na aprendizagem, e ainda identificar o seu papel neste contexto escolar. Os referidos autores contemplam 
que as teorias de aprendizagem podem auxiliar os professores neste contexto escolar, pois possibilitam reconhecer a dinâmica dos atos de ensinar e aprender, por meio da identificação do desenvolvimento cognitivo da criança. As teorias de aprendizagem proporcionam bases para o desenvolvimento de estratégias de ensino para as séries iniciais, fundamentadas no lúdico e nas brincadeiras.

O lúdico e as brincadeiras são estratégias de ensino aplicadas também nas séries iniciais do ensino fundamental, pois as suas aplicações não se restringem ao processo de ensino-aprendizagem das séries iniciais. Cardia (2011) aborda que o lúdico e a brincadeira são estratégias fundamentais para o desenvolvimento e aprendizagem de todas as crianças, pois o lúdico contribui e influencia a aprendizagem dos conteúdos escolares, e ainda auxilia no desenvolvimento dos componentes cognitivos, afetivos e psicomotores. A referida autora ressalva que a aplicação de atividades lúdicas e recreativas nas séries iniciais apresentam dificuldades aos professores, pois eles não possuem as horas-atividades suficientes para o planejamento deste tipo de aulas. O planejamento destas aulas envolve a definição de conexão entre a ludicidade e as brincadeiras com os conteúdos da aula.

Gonçalves (2010) ressalta que não há diversificação dos instrumentos avaliativos no ensino fundamental, pois os mais utilizados são: as provas, os trabalhos, as pesquisas, as observações e os pareceres descritivos. Ao abordar sobre as séries iniciais, a referida autora observa que os instrumentos avaliativos são geralmente utilizados nas terceira e quarta séries, com atribuição de notas elevadas e para verificação de conhecimentos no aprendizado do aluno. A definição dos instrumentos avaliativos deve considerar os objetivos do processo de ensinoaprendizagem e o diagnóstico dos alunos e das turmas, para se apresentarem adequados ao contexto das séries iniciais do ensino fundamental.

Tonche (2014) identifica o desinteresse da educação escolar pelos alunos das séries iniciais do ensino fundamental. A referida autora aponta as seguintes motivações destes alunos: a política falha do sistema educacional; professores desvalorizados; condições inadequadas de infraestrutura dos prédios; a inadequação dos métodos de ensino; priorização da quantidade no sistema de aprovação; carências 
afetivas; deficiências no atendimento das necessidades básicas; ausência do comprometimento familiar e do aluno; dificuldades de aprendizagem; e a evasão escolar.

Estes fatores motivacionais evidenciam os pontos em que professores, famílias e o Estado devem atuar para tratar deste problema do desinteresse dos alunos das séries iniciais pela educação escolar. Menezes e Trevisol (2010) evidenciam a necessidade de reorganização do espaço escolar, para garantir o acesso à escola e transformá-la em um lugar agradável e atrativo, para o aluno permanecer por ser muito divertido e prazeroso. Este contexto agradável é propício para o desenvolvimento da aprendizagem dos alunos nas séries iniciais do ensino fundamental.

Santos e Ghelli (2015) destacam que a aprendizagem não é somente a inteligência e construção do conhecimento, mas envolve também a identificação pessoal, o caráter, a formação humana, a socialização e a relação social. No desenvolvimento da aprendizagem, os referidos autores identificam os seguintes fatores centrais na prática escolar: o aluno, o professor, as diversas situações e objetos de aprendizagem, e a participação da família no acompanhamento, na orientação dos alunos.A compreensão dos elementos centrais da prática escolar possibilita trabalhar um processo de ensino-aprendizagem que promova o interesse dos alunos das séries iniciais do ensino fundamental.

Pery, Cardoso e Nunes (2010) salientam que o ensino nas séries iniciais deve contemplar um espaço rico em vivências, constituído a partir da compreensão do mundo da criança, de suas necessidades e capacidades. De acordo com os autores, o professor precisa trabalhar uma abordagem diferenciada, promovendo atividades que produzam conflitos cognitivos e, consequentemente, contribuam para o desenvolvimento de novas hipóteses e a construção de novas estruturas de conhecimentos.

As estratégias se apresentam como instrumentos que potencializam o desenvolvimento da ludicidade nas atividades do processo de ensino-aprendizagem das séries iniciais. Niles e Socha (2014) observam que as diversas modalidades lúdicas 
não se apresentam em todas as épocas e são mutáveis no decorrer dos tempos. As referidas autoras constatam que as atividades lúdicas possuem um significado para as crianças, que envolve a forma de lidarem os seus sentimentos, de esperar a sua vez, de buscarem compreenderem as regras e de desenvolverem as interações.

As atividades lúdicas são manifestadas em diversas formas de jogos e de brincadeiras. Kishimoto (2010) classifica as atividades lúdicas da seguinte forma: jogos educativos, instrumento de situações de aprendizagem que trabalha os componentes físico, cognitivo, afetivo e social; brincadeiras tradicionais infantis: oriundas de manifestações livre e espontânea da cultura popular, com a presença do lúdico; brincadeiras de faz-de-conta, fundamentadas em simbolismo, envolvendo o imaginário e regras implícitas; e brincadeiras de construção, atividades agregadoras à experiência sensorial, criatividade e desenvolvimento de habilidades.

Reverdito et al (2013) observam que os jogos lúdico-motores se apresentam suprimidos no ambiente escolar, apesar de serem reconhecidos como importantes no desenvolvimento dos alunos das séries iniciais. Os referidos autores relatam que os jogos educativos estão condicionados pelo olhar dirigido para as crianças aprenderem conteúdo sério ou na condição de diversão. As potencialidades dos jogos não são suficientes para sua aplicação no processo de ensino-aprendizagem, demanda-se diversas fundamentações.

Niles e Socha (2014) destacam que o lúdico é desafiador, pois o educador deve ser detentor de uma fundamentação teórica bem estruturada e de consciência em relação à uma criança inserida no contexto tecnológico. Reverdito et al (2013) abordam que a aplicação dos jogos se condiciona também ao convencimento dos professores e dos pais em relação à importância destes instrumentos no desenvolvimento das crianças.

As atividades lúdicas podem ser utilizadas para abordar conteúdo de diversos temas importantes na formação cidadão dos alunos das séries iniciaisção alimentar por meio de jogos e brincadeiras, com enfoque nas relações do mundo real da criança com o mundo e nos estímulos no ensino de nutrição, no ato de experimentar novos alimentos e na participação do preparo de alimentos simples. Estas atividades lúdicas 
possibilitam transformar os hábitos alimentares para uma condição mais saudável, em um contexto de fácil acesso das crianças aos alimentos muito calóricos.

A cooperação nas séries iniciais pode ser trabalhada pelas atividades lúdicas, com a mediação do professor. Palmieri (2015) ressalta que as atividades lúdicas de cooperação contribuem para os alunos construírem valores relacionados à sua autonomia para coordenação de suas atitudes. A referida autora complementa que estas atividades lúdicas possibilitam aos professores aprimorarem a exploração das configurações motivacionais e facilitadoras de modalidades construtivistas de interdependência social. Estas atividades lúdicas de cooperação são recursos didáticos para apoiar os alunos no desenvolvimento de reflexões e concepções sobre as relações sociais do seu cotidiano.

Moura, Cribb e Jeovanio-Silva (2016) identificam a aplicação de atividades lúdicas para abordar os conhecimentos da educação ambiental junto aos alunos das séries iniciais, por meio das estratégias de plantio de hortas, dramatização e montagem de brinquedos. As constatações destes autores evidenciam que a conscientização ambiental pode ser iniciada nas séries iniciais. As crianças podem se constituir agentes de disseminação dos conhecimentos de conscientização ambiental junto aos seus familiares e à comunidade.

Os conhecimentos da ludopedagogia proporciona o aprimoramento das atividades lúdicas, pois o trabalho com a ludicidade deve observar as mudanças provenientes do desenvolvimento das crianças. As atividades lúdicas se constituem como estratégias no processo de ensino-aprendizagem das séries iniciais, para abordagem de diversos conhecimentos por meio de brincadeiras e jogos. Apesar de se embasarem brincadeiras e jogos, demandam planejamento, mas não deve retirar a liberdade das crianças para atendimento da racionalidade no processo de ensinoaprendizagem das crianças nas séries iniciais.

\section{CONSIDERAÇÕES FINAIS}

A ludopedagogia possibilita desenvolver o aprofundamento dos conhecimentos que envolvem as atividades lúdicas no processo de ensino- 
aprendizagem, considerando também as práticas pedagógicas e a aprendizagem das crianças nas séries iniciais. De acordo com as bases de conhecimentos da ludopedagogia, as estratégias de ensino se desenvolvem por meio de recursos facilitadores da aprendizagem e estimuladores de criatividade.

As atividades lúdicas se desenvolvem por meio dos recursos de jogos, brincadeiras e dinâmicas, que estimulam a socialização, a comunicação, a expressão e a construção do conhecimento. Estas atividades lúdicas dialogam com o desenvolvimento dos alunos no processo de ensino-aprendizagem, sendo selecionadas conforme as demandas deles. Portanto, a ludopedagogia possibilita ao professor trabalhar os desafios do processo de ensino-aprendizagem das séries iniciais, inclusive pensar o aluno em sua totalidade para propor uma educação significativa e de qualidade.

A ludicidade difere das atividades lúdicas, pois ela é uma característica inerente às elas. As dimensões da ludicidade são: a cultural, a psicológica e a pedagógica. Estas dimensões se dialogam entre si, para a construção de práticas pedagógicas que contemplem os aspectos da ludicidade no processo de ensinoaprendizagem. As atividades lúdicas trabalham a criatividade, e o desenvolvimento físico e sensorial das crianças, por meio de ações prazerosas que possibilitam o compartilhamento e expressão de sua individualidade e identidade. As manifestações de ludicidade envolvem negociação, protagonismo e decisão, consolidando o aluno sujeito ativo na construção do seu conhecimento no processo de ensinoaprendizagem. Observa-se que os fatores curiosidade e criatividade se constituem os fatores impulsionadores da concretização dos objetivos das atividades lúdicas.

O desenvolvimento do processo de ensino-aprendizagem das séries iniciais demanda uma compreensão do professor em relação às formas de aprendizagem das crianças, as condições e objetos de aprendizagem. Após compreendido estes elementos, o professor deve reconhecer o seu papel neste processo de ensinoaprendizagem. As teorias de aprendizagem fomentam a sua prática docente, identificando o potencial do lúdico e das brincadeiras nas estratégias de ensino nas séries iniciais. $O$ lúdico $e$ as brincadeiras influenciam a aprendizagem e o 
desenvolvimento das crianças, pois trabalham os fatores cognitivos, afetivos e psicomotores. A definição do instrumento avaliativo demanda considerar os objetivos do processo de ensino-aprendizagem e o diagnóstico dos alunos.

Nas séries iniciais do ensino fundamental, o desinteresse da educação escolar pelos alunos pode ser fundamentado por diversas motivações, conforme cada caso. Essas motivações indicam caminhos para se trabalhar a evasão escolar nestas séries do ensino fundamental. A aprendizagem não pode se restringir ao processo de construção do conhecimento, pois envolvem fatores sociais, psicológicos e físicos inerentes ao processo de ensino-aprendizagem. A aprendizagem nas séries iniciais demanda um espaço de vivências, que possibilite a construção de novas estruturas de conhecimentos.

As atividades lúdicas não são imutáveis, pois se desenvolvem influenciadas pelas dimensões da ludicidade. As crianças produzem significados durante a participação nas atividades lúdicas, que se manifestam na espera da sua vez, nos seus sentimentos e na compreensão das normas e das ações. Estas atividades lúdicas são classificadas em: jogos educativos, brincadeiras tradicionais infantis, brincadeiras de faz-de-conta e brincadeiras de construção.

Os jogos educativos e as brincadeiras são selecionados em conformidade com o olhar dirigido às crianças, e ao convencimento de sua importância junto aos pais e professores. Pode-se utilizar as atividades lúdicas de cooperação, que são recursos didáticos que possibilitam a exploração das configurações motivacionais e facilitadoras de modalidades construtivistas de interdependência social. Nestas atividades lúdicas, os professores podem aplicar a abordagem de diversos temas que são componentes da formação cidadã da criança.

Desta maneira, conclui-se que as estratégias de ensino lúdicas são embasadas pelos conhecimentos difundidos na ludopedagogia, se expressando por meio de atividades lúdicas de jogos, brincadeiras e dinâmicas. Estas estratégias de ensino lúdicas se desenvolvem embasadas na criatividade e curiosidade da criança, contribuindo para o aluno se posicionar como agente ativo na construção dos eu conhecimento. Os objetivos do processo de ensino-aprendizagem devem estar 
presentes nestas estratégias de ensino lúdicas, pois somente brincar não significa o desenvolvimento de aprendizagem nas séries iniciais.

\section{REFERÊNCIAS}

ALVES, Lucas Henrique Barbosa; BATISTA, Igor Mateus; PAULO, Renato. A ludopedagogia no desenvolvimento infantil. In: Jornada de Pedagogia da Unespar, I4, 2019, Paranavaí. Anais eletrônicos. Paranavaí: UNESPAR, 2019. Disponível em: $<$ http://paranavai.unespar.edu.br/graduacao/graduacao/pedago giaI/eventos/ANAISXIVJORPED2019.pdf \#page=56>.Acesso em i4 de julho de 2021.

BEZERRA, Edneide da Conceição. A tecitura da ação do coordenador pedagógico da EJA: saberes necessários à mediação do trabalho docente em alfabetização. 2009. $258 \mathrm{f}$. Tese (Doutorado em Educação), Universidade Federal do Rio Grande do Norte, Natal, 2009.

CALABRESI, Regina Páscoa Mazeto. Ludopedagogia: aspectos importantes para a educação. 2015. 18F. Trabalho de Conclusão de Curso (Especialização em Educação: Métodos e Técnicas de Ensino), Universidade Tecnológica Federal do Paraná, Medianeira, 2015.

CARDIA, Joyce Aparecida Pires. A importância da presença do lúdico e da brincadeira nas séries iniciais: um relato de pesquisa. Revista Eletrônica de Educação, v. 5, n. 9, p. I-I4, 20II. Disponível em: 〈http://videocamp-produs.s3.amazonaws.com/uploads/lesson_plan_attachment/file/ooo/ooo/oo2/2/A_IMP ORT_NCIA_DA_PRESEN_A_DO_L_DICO_E_DA_BRINCADEIRA_NAS_S_RIE S.pdf >. Acesso em I4 de julho de 202I.

CERVINSKI, Grazieli Maria. A ludicidade no ensino de História. 2019.48f. Trabalho de Conclusão de Curso (Licenciatura em História), Universidade Federal da Fronteira Sul, Erechim, 2019. 
CORDAZZO, Sheila T. D. et al. A Brincadeira e suas Implicações no Processo de Aprendizagem e Desenvolvimento. In: Estudos e Pesquisas em Psicologia. Rio de Janeiro: UERJ, 2007.

FREIRE, Patricia de Oliveira. A inclusão de crianças com necessidades educacionais especiais em processo de alfabetização: o lúdico como recurso para a aprendizagem. 20II. IIof. Trabalho de Conclusão de Curso (Licenciatura em Pedagogia), Universidade Brasília, Brasília, 2orr.

GONÇALVES, Andréia. O desafio da avaliação nas séries iniciais do ensino fundamental. 20I0. 46f. Trabalho de Conclusão de Curso (Graduação em Pedagogia). Universidade Estadual de Londrina. Londrina, 2010.

KISHIMOTO, TizukoMorchida. Brinquedos e brincadeiras na Educação Infantil. Seminário Nacional: Currículo em Movimento - Perspectivas Atuais, I, 2010, Belo Horizonte. Anais. Belo Horizonte; UFMG, 2010.

LANES, Dário Vinícius Ceccon et al. Estratégias lúdicas para a construção de hábitos alimentares saudáveis na educação infantil. Revista Ciências \& Ideias, v. 4, n. I, 2012. Disponível em: 〈https://revistascientificas.ifrj.edu.br/revista/ index.php/reci/article/view/I35>.Acesso em I4 de julho de 202I.

LOPES, Carine Penha Andrello. A ludopedagogia e a manutenção da atenção do aluno. 2013.43f. Monografia (Especialização em Pós Graduação em Educação: Métodos e Técnicas de Ensino), Universidade Tecnológica Federal do Paraná, Medianeira, 2013.

LUCKESI, Cipriano. Ludicidade e formação do educador. Revista Entreideias, Salvador, v. 3, n. 2, p. 13-23, jul./dez. 2014. Disponível em: 〈https://ciencias 
medicasbiologicas.ufba.br/index.php/entreideias/article/view/9168>. Acesso em I4 de julho de 202I.

MARIANO, Eliane Pereira de Souza. A importância do brincar na visão ludopedagógica no desenvolvimento infantil. 2012. 46f. Monografia (Especialização em Pós Graduação em Educação: Métodos e Técnicas de Ensino), Universidade Tecnológica Federal do Paraná, Medianeira, 2012.

MENEZES, Sheila Beatriz Sehnem; TREVISOL, Maria Teresa Ceron. O aprender e o não aprender na escola: a ótica de alunos das séries iniciais do Ensino Fundamental com dificuldades de aprendizagem. Revista Contexto \& Educação, v. 25, n. 84, p. 77-Ior, 20I0. Disponível em:<https://revistas.unijui. edu.br/index.php/contextoeducacao/ article/view/989>. Acesso em I4 de julho de 2021.

MINEIRO, Márcia; D’ÁVILA, Cristina. Ludicidade: compreensões conceituais de pós-graduandos em educação. Educação e Pesquisa, v. 45, 2019. Disponível em: $\langle$ https://www.scielo.br/scielo.php?pid=S1517-97022019000100587\&script $=$ sci_arttext $>$. Acesso em I4 de julho de 202I.

MOURA, Jaqueline Senna Targueta de; CRIBB, Sandra Lucia de Souza Pinto; JEOVANIO-SILVA, André Luiz. Vivência de atividades práticas e lúdicas na Educação Ambiental de crianças de 4-5 anos: o despertar da consciência ecológica e estímulo á motivação profissional e interação aluno-professor. Revista Brasileira de Educação Ambiental (RevBEA), v. II, n. I, p. 361-384, 2016. Disponível em: $\langle$ http://revbea.emnuvens.com.br/revbea/ article/view/45I4〉. Acesso em I4 de julho de 202I.

NILES, Rubia Paula; SOCHA, Kátia. A importância das atividades lúdicas na educação infantil. ÁGORA: Revista de divulgação científica, v. 19, n. I, p. 80-94, 2014. 
Disponível em: < http://www.periodicos.unc.br/index.php/agora/article/ view/350 $>$.Acesso em I4 de julho de 2021.

PALMIERI, MariliciaWitzler Antunes Ribeiro. Jogos cooperativos e a promoção da cooperação na educação infantil. Psicologia Escolar e Educacional, v. I9, n. 2, p. 243252, 2015. Disponível em: <https://www.scielo.br/scielo.php? pid=Si413$85572015000200243 \&$ script $=$ sci_arttext $\& \operatorname{lng}=$ pt $>$.Acesso em I4 de julho de 2021.

PERY, Liliana Cristina; CARDOSO, Sheila Pressentin; NUNES, Wallace Vallory. Jogos Educativos Digitais: ludicidade e interatividade no ensino nas séries iniciais. In: Congresso Iberoamericano de Informática Educativa, I, 20Io, Santiago do Chile. Anais eletrônicos... Santiago do Chile: IE, 2oro. Disponível em:<http://www.tise.cl/ volumen6/TISE2oro/Documentor6.pdf $>$. Acesso em i4 de julho de 2021.

REVERDITO, Riller Silva et al. O cotidiano da criança na Instituição de Ensino: Espaço e tempo disponível para atividades lúdico-motoras. Pensar a prática, v. ı6, n. 2, 2013. Disponível em: 〈https://www.revistas.ufg.br/fef/article/view/ I6809〉. Acesso em i4 de julho de 2021.

SANTOS, Anderson Oramísio; GHELLI, Kelma Gomes Mendonça. Implicações das teorias behavioristas e cognitivistas na aprendizagem matemática nas séries iniciais do ensino fundamental. In: Anais do Encontro de Pesquisa em Educação, 8,2015, Uberaba.Anais eletrônicos... Uberaba: Uniube, 2015. Disponível em: $\langle$ https://www. uniube.br/eventos/epeduc/2015/completos/72.pdf $>$. Acesso em I4 de julho de 202I.

SANTOS, Santa Marli Pires dos. O brincar na escola: Metodologia Lúdicovivencial, coletâneas de jogos, brinquedos e dinâmicas. 2 ed. Petrópolis, RJ: Vozes, 201 I. 
SILVA, Joana F. M. da. Atividades Ludopedagógicas e Intervenção Comunitária. Lisboa: Universidade de Lisboa, 2012.

TONCHE, Josiane Cipriano da Silva. O desinteresse dos alunos das séries iniciais do ensino fundamental pela educação escolar: causas e possíveis intervenções. 2014.2of. Trabalho de Conclusão de Curso (Especialização em Coordenação Pedagógica), Universidade Federal do Paraná, Curitiba, 2014.

VOTTO, Thays Rodrigues; PORCIÚNCULA, Mauren. A ludicidade como estratégia pedagógica. Revista de estudios e investigaciónenpsicología y educación, n. I, p. 20I-205, 2017. Disponível em: <https://dialnet.unirioja.es/ servlet/articulo?codigo=624II79>. Acesso em I4 de julho de 202I. 